\title{
ON THE OCCURRENCE OF YELLOW SEEDLINGS IN A VARIEGATED STRAIN OF RICE*
}

\author{
Yoshiwo Katayama and Shojiro Shida \\ Laboratory of Plant Breeding, Faculty of Agriculture Miyazaki, University, \\ Miyazaki, Japan
}

UDC 582. 542. $1: 633$. $18: 631.531 .12$.

\section{Introduction}

The authors found a mutated line showing yellow seedlings in a variegated strain of rice named Fukui-jima (Katayama and Shida, 1954). Generally the yellow seedlings became green from near the vein of leaf on $5 \sim 6$ days after germination. Thus after 8 9 days they showed a mosaic feature which was maintained for about one week, and then almost became usual green leaves.

Regarding such yellow individuals of rice, some reports are already seen such as those of Morinaga (1932), Hara (1944, 1946), and others. Two types are classified as chlorina and xantha. The authors' yellow line belongs to the chlorina type, but it seems to have a completely new character due to the following points, namely, (1) expression only at the seedling stage and (2) behavior as a maternal inheritance. Since this new character seems to be influenced by the seasonal temperature, some investigations were chiefly done in relation to it.

\section{Experimental data}

(1) Temperature treatment at germination

The feature of yellow seedlings was indistinct in one year, but it seemed to be clear when sowed in a season of low temperature. Therefore a test for temperature was done at the stage of germination. In late July of 1953-54, materials (sowed in sand dish) treated for 2 3 days with water were maintained (in thermostat) for 3 5 days at temperatures $5,10,15,18,21,25$ and $40^{\circ} \mathrm{C}$ respectively. Then they were removed to the usual room $\left(c a .30^{\circ} \mathrm{C}\right)$ and the colour of seedling leaves was observed. From this result (Table 1) the 2 nd leaf of seedlings maintained at $15^{\circ} \mathrm{C}$ showed yellow clearly, but no reaction around $30^{\circ} \mathrm{C}$ (room temperature). Moreover, at a temperature as low as $5^{\circ} \mathrm{C}$ the change of colour was indistinct, perhaps depending upon almost stoppage of growth. At a high temperature of $40^{\circ} \mathrm{C}$, the leaf also became somewhat yellow due to inhibition of chlorophyll formation.

* Contributions from the Laboratory of Plant Breeding, Faculty of Agriculture, Miyazaki University, No. 10 . 
Table 1 Temperature treatment at germination (5 days)

\begin{tabular}{|c|c|c|c|c|c|c|c|c|c|c|c|}
\hline \multirow{2}{*}{\multicolumn{2}{|c|}{$\begin{array}{l}\text { Days after } \\
\text { treatment }\end{array}$}} & \multirow{2}{*}{ Location of leaf } & & \multicolumn{7}{|c|}{ Temperature of treatment $\left({ }^{\circ} \mathrm{C}\right)$} & \multirow{2}{*}{ Control $^{2)}$} \\
\hline & & & & 5 & 10 & 15 & 18 & 21 & 25 & $40^{1)}$ & \\
\hline \multirow{4}{*}{\multicolumn{2}{|c|}{3}} & Prophyll & & $+3)$ & + & + & + & + & + & + & + \\
\hline & & 1 st leaf & & + & + & + & + & + & + & + & + \\
\hline & & 2 nd $"$ & & . & . & . & $\cdot$ & $\cdot$ & . & . & . \\
\hline & & $3 \mathrm{rd} "$ & & $\cdot$ & $\cdot$ & $\cdot$ & $\cdot$ & $\cdot$ & $\cdot$ & $\cdot$ & $\cdot$ \\
\hline & \multirow{4}{*}{6} & Prophyll & & + & + & + & + & + & + & + & + \\
\hline & & 1 st leaf & & + & + & + & + & + & + & + & + \\
\hline & & 2 nd $"$ & & $\cdot$ & $-4)$ & - & - & \pm & + & \pm & + \\
\hline & & $3 \mathrm{rd} "$ & & . & . & . & $\cdot$ & $\cdot$ & . & . & . \\
\hline & \multirow{4}{*}{9} & Prophyll & & + & + & + & + & + & + & + & + \\
\hline & & 1 st leaf & & + & + & + & + & + & + & + & + \\
\hline & & 2 nd $"$ & & \pm & \pm & - & - & \pm & + & \pm & + \\
\hline & & $3 \mathrm{rd} "$ & & $\cdot$ & $\cdot$ & $\cdot$ & $\cdot$ & $\cdot$ & $\cdot$ & $\cdot$ & $\cdot$ \\
\hline \multirow{4}{*}{\multicolumn{2}{|c|}{12}} & Prophyll & & + & + & + & + & + & + & + & + \\
\hline & & 1 st leaf & & + & + & + & + & + & + & + & + \\
\hline & & 2 nd $"$ & & \pm & \pm & - & \pm & + & + & + & + \\
\hline & & $3 \mathrm{rd} "$ & & $\cdot$ & + & + & + & + & + & + & + \\
\hline \multirow{4}{*}{\multicolumn{2}{|c|}{15}} & Prophyll & & + & + & + & + & + & + & + & + \\
\hline & & 1 st leaf & & + & + & + & + & + & + & + & + \\
\hline & & 2 nd $"$ & & + & + & \pm & \pm & + & + & + & + \\
\hline & & $3 \mathrm{rd} "$ & & + & + & + & + & + & + & + & + \\
\hline
\end{tabular}

\section{(2) Days after wetting of seeds}

The result mentioned above is that of materials treated after sowing in sand dish after 2 3 days from the wetting. The time required for wetting in the test were disposed as 0 (control), 1/4 (6 hours), 1/2 (12 hours), 1, 2, 3, 5, 7 and 9 days respectively after immersion. Then the materials were placed in two thermostats, regulated at $10^{\circ} \mathrm{C}$ (5 days) and $40^{\circ} \mathrm{C}$ (3 days). In late July, the seeds generally begin their germination in $2 \sim 3$ days after wetting when they are placed in the usual room, in 5 days occur both of the prophyll and the 1 st leaf, and then in 7 days the 2 nd leaf appears. The result of treatment, as can be seen in Table 2, denoted no yellow leaf in the one day wetted material, but was distinct in that of 2 or more days. The results shown in Table 2 of the $10^{\circ} \mathrm{C}$ experiment were obtained chiefly in the year 1954, and partly in the preliminary 1953 test. But the results of $40^{\circ} \mathrm{C}$ were obtained only in 1953 . Moreover the series at $10^{\circ} \mathrm{C}$ showed clearly yellow leaves in materials treated after 3 days from wetting, but those of 5 or more days became gradually indistinct. And the series at $40^{\circ} \mathrm{C}$ appeared clearly in the material of 5 days. 
Table 2 Days after wetting of seeds

\begin{tabular}{|c|c|c|c|c|c|c|c|c|c|c|c|c|c|c|}
\hline \multirow{3}{*}{$\begin{array}{c}\text { Days after } \\
\text { treatment }\end{array}$} & \multirow{3}{*}{$\begin{array}{l}\text { Location } \\
\text { of leaf }\end{array}$} & \multirow{3}{*}{0} & \multirow{3}{*}{$1 / 4$} & \multicolumn{5}{|c|}{ Days after wetting $\left(10^{\circ} \mathrm{C}\right)$} & \multirow{3}{*}{7} & \multirow{3}{*}{9} & \multirow{2}{*}{\multicolumn{4}{|c|}{$\begin{array}{c}\text { Days after } \\
\text { wetting }\left(40^{\circ} \mathrm{C}\right)\end{array}$}} \\
\hline & & & & $1 / 2$ & 1 & 2 & 3 & 5 & & & & & & \\
\hline & & & & & & & & & & & $1 / 4$ & 2 & 5 & 7 \\
\hline \multirow{4}{*}{3} & Prophyll & $\cdot$ & $\cdot$ & • & $\cdot$ & + & + & + & + & + & + & + & + & + \\
\hline & 1 st leaf & $\cdot$ & • & - & . & - & + & + & + & + & . & + & + & + \\
\hline & 2 nd $" \prime$ & . & . & - & . & . & . & . & . & \pm & . & . & - & - \\
\hline & $3 \mathrm{rd} " \prime$ & . & . & . & . & . & . & . & . & . & . & . & . & . \\
\hline \multirow{4}{*}{6} & Prophyll & + & + & + & + & + & + & + & + & + & $\begin{array}{c}- \\
+\end{array}$ & + & + & + \\
\hline & 1 st leaf & + & + & + & + & + & + & + & + & + & + & + & + & + \\
\hline & 2 nd $" \prime$ & · & $\cdot$ & $\cdot$ & . & . & - & - & - & \pm & + & \pm & - & - \\
\hline & $3 \mathrm{rd} " \prime$ & $\cdot$ & $\cdot$ & $\cdot$ & - & $\cdot$ & • & - & - & $\cdot$ & - & - & • & • \\
\hline \multirow[t]{4}{*}{$\ldots$} & Prophyll & + & + & + & + & + & + & + & + & + & + & + & + & + \\
\hline & 1 st leaf & + & + & + & + & + & + & + & + & + & + & + & + & + \\
\hline & 2 nd $"$ & $t$ & + & + & + & - & - & - & \pm & + & + & \pm & - & \pm \\
\hline & 3 rd $\prime \prime$ & $\cdot$ & . & . & . & $\cdot$ & $\cdot$ & . & $\cdot$ & - & - & $\cdot$ & + & + \\
\hline \multirow{4}{*}{12} & Prophyll & + & + & + & + & + & + & + & + & + & + & + & + & + \\
\hline & 1 st leaf & + & + & + & + & + & + & + & + & + & + & + & + & + \\
\hline & 2 nd $" \prime$ & + & + & + & + & \pm & - & \pm & \pm & + & + & + & - & \pm \\
\hline & $3 \mathrm{rd} \quad \prime$ & • & . & - & . & + & + & + & + & + & + & + & + & + \\
\hline \multirow{4}{*}{15} & Prophyll & + & + & + & + & + & + & 7 & + & + & + & + & + & + \\
\hline & 1 st leaf & + & + & + & $t$ & + & + & + & + & + & + & + & + & + \\
\hline & 2 nd $"$ & + & + & + & + & \pm & - & \pm & + & + & + & + & \pm & \pm \\
\hline & $3 \mathrm{rd} " \prime$ & - & . & . & + & + & + & + & + & + & + & + & + & + \\
\hline
\end{tabular}

(3) Days of treatment at germination

The treatment under low temperature $\left(10^{\circ} \mathrm{C}\right)$ was carried out in series of 1,2 , 4, 6, 8, 10 days. This experiment was chiefly done in late July of 1954 , and partly in 1953, the result being shown in Table 3. This result shows that no yellow leaf appears in the 2 days treated material, and yellowness scarecely shows after 4 days, with the longer days showing the clearer result.

Table 3 Days of treatment at germination $\left(10^{\circ} \mathrm{C}\right)$

\begin{tabular}{|c|c|c|c|c|c|c|c|c|c|}
\hline & Days after & Location & & & ys & atn & & & \\
\hline & treatment & of leaf & 1 & 2 & 4 & 6 & 8 & 10 & \\
\hline & & Prophyll & + & + & + & + & + & + & \\
\hline & 3 & 1 st leaf & + & + & + & + & + & + & \\
\hline & & 2 nd $" \prime$ & - & • & - & - & $\cdot$ & $\cdot$ & \\
\hline & & $3 \mathrm{rd} " \prime$ & . & - & - & . & - & $\cdot$ & \\
\hline$\cdots$ & ...- & Prophyll & $\cdots$ & + & + & + & + & $-t$ & \\
\hline & $c$ & 1 st leaf & $t$ & + & $\dot{+}$ & + & $\dot{t}$ & + & \\
\hline & 0 & 2 nd $\prime \prime$ & + & + & - & - & - & - & \\
\hline & & $3 \mathrm{rd} \prime \prime$ & - & $\cdot$ & $\cdot$ & · & $\cdot$ & $\cdot$ & \\
\hline
\end{tabular}




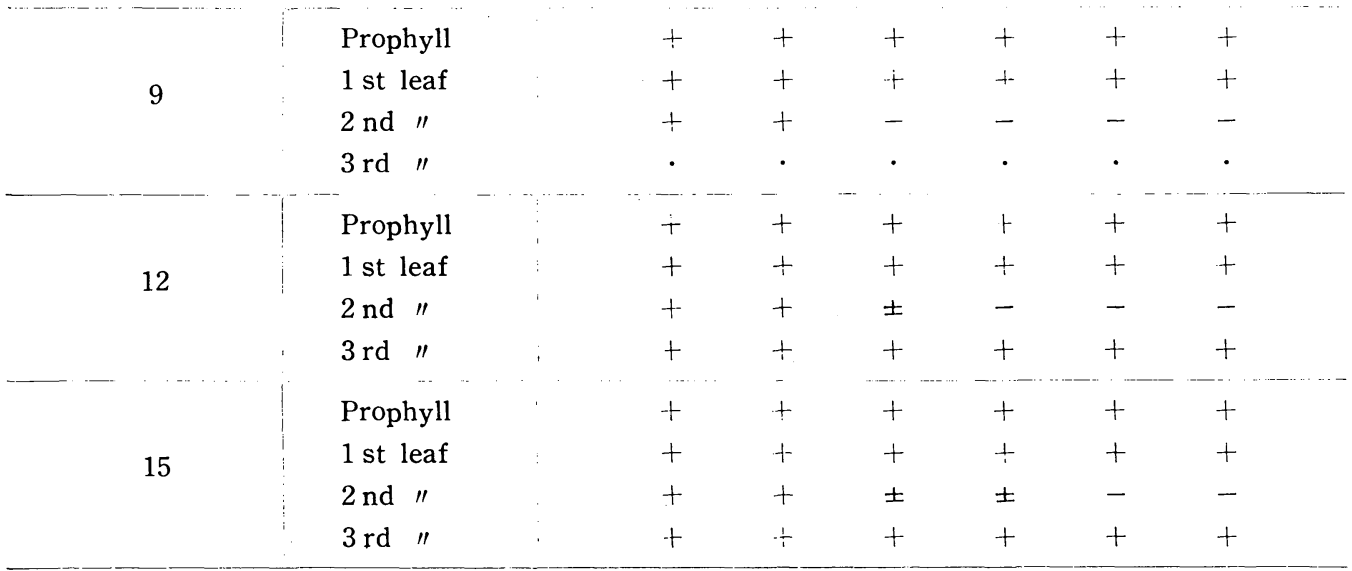

(4) Treatment for various strains of rice

The authors intended to know whether the treatment for low temperature relates or not to the other lines and strains. As materials, they used the typical and green lines from the variegated rice, as well as normal green strain (Zuiho), another yellow strain (Kogane-nishiki), Purple strain (Murasaki-ine) and other special ones (Murasaki-muyozetsuto, Bunketsuto, Muketsuto, Sankaku-ine, Koto, Tanko-foira). The 5 days treatment with low temperature $\left(10^{\circ} \mathrm{C}\right)$ was chiefly done in 1954 and partly in 1953. The results are shown in Table 4. All the materials without the line in question did not appear.

Table 4 Treatment for various strains of rice $\left(10^{\circ} \mathrm{C}\right)$

\begin{tabular}{|c|c|c|c|c|c|c|c|c|c|c|c|c|c|}
\hline \multirow{2}{*}{$\begin{array}{l}\text { Days after } \\
\text { treatmnet }\end{array}$} & \multirow[b]{2}{*}{$\begin{array}{c}\text { Location } \\
\text { of leaf }\end{array}$} & \multicolumn{3}{|c|}{ Fukui-jima } & \multirow{2}{*}{ 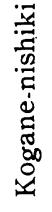 } & \multirow{2}{*}{ 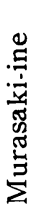 } & \multirow{2}{*}{ 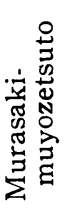 } & \multirow[b]{2}{*}{ 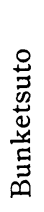 } & \multirow[b]{2}{*}{ 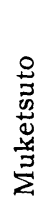 } & \multirow{2}{*}{ 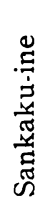 } & & \multirow[b]{2}{*}{ 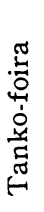 } & \multirow[b]{2}{*}{ 곡 } \\
\hline & & $\frac{3}{2}$ & 胥 & م્屯 & & & & & & & $\underset{\substack{0 \\
0}}{2}$ & & \\
\hline \multirow{4}{*}{3} & Prophyll & + & + & + & + & + & + & + & + & + & + & + & + \\
\hline & 1 st leaf & + & + & + & + & + & + & + & + & + & + & + & t \\
\hline & $2 \mathrm{nd} \quad "$ & $\cdot$ & $\cdot$ & $\cdot$ & . & $\cdot$ & - & $\cdot$ & $\cdot$ & . & - & $\cdot$ & $\cdot$ \\
\hline & 3 rd $"$ & $\cdot$ & $\cdot$ & $\cdot$ & $\cdot$ & $\cdot$ & . & $\cdot$ & . & . & • & $\cdot$ & $\cdot$ \\
\hline \multirow{4}{*}{6} & Prophyll & + & + & + & + & + & + & + & + & + & + & + & + \\
\hline & $1 \mathrm{st}$ leaf & + & + & + & + & + & + & + & + & + & + & + & + \\
\hline & 2 nd $" \prime$ & - & + & + & $\dot{t}$ & + & + & + & + & + & $+t$ & + & + \\
\hline & $3 \mathrm{rd}$ & $\cdot$ & $\cdot$ & $\cdot$ & $\cdot$ & $\cdot$ & $\cdot$ & $\cdot$ & $\cdot$ & $\cdot$ & $\cdot$ & $\cdot$ & $\cdot$ \\
\hline \multirow{4}{*}{9} & Prophyll & + & + & + & + & + & + & + & + & + & $\div$ & + & + \\
\hline & 1 st leaf & + & $\dot{+}$ & + & + & + & + & $t$ & + & + & + & + & + \\
\hline & 2 nd & - & + & + & + & + & + & + & + & + & + & + & + \\
\hline & 3 rd $"$ & $\cdot$ & $\cdot$ & $\cdot$ & $\cdot$ & $\cdot$ & $\cdot$ & $\cdot$ & $\cdot$ & $\cdot$ & $\cdot$ & $\cdot$ & $\cdot$ \\
\hline
\end{tabular}




\begin{tabular}{|c|c|c|c|c|c|c|c|c|c|c|c|c|c|}
\hline \multirow{4}{*}{12} & Prophyll & + & $\dot{r}$ & + & + & t. & $+t$ & + & + & + & + & + & + \\
\hline & 1 st leaf & + & + & + & + & + & + & + & + & + & + & $\dot{+}$ & + \\
\hline & 2 nd $"$ & - & + & + & + & + & + & + & + & + & + & + & + \\
\hline & $3 \mathrm{rd} "$ & + & + & + & + & + & + & + & + & + & + & + & + \\
\hline \multirow{4}{*}{15} & Prophyll & + & + & + & + & + & + & + & + & + & + & + & + \\
\hline & 1 st leaf & + & $\dot{r}$ & + & + & + & + & + & + & + & + & + & + \\
\hline & 2 nd $"$ & \pm & + & + & + & + & + & + & + & + & + & + & + \\
\hline & $3 \mathrm{rd} "$ & + & + & + & + & + & + & + & + & + & + & + & + \\
\hline
\end{tabular}

(5) Sowing time and degree of yellow appearance

The relation between sowing time and degree of yellow-appearance was compared, sowing in April 20, May 5, June 15, July 15, August 15 and September 20 respectively. A preliminary test was made in 1953 and exact one in 1954. The degree with respect to different location of leaves was identified by 6 classes denoting from 0 (complete green) to 5 (complete yellow). From this result yellow leaf was observed until the $3 \mathrm{rd}$ leaf at the seedling stage. Among these leaves the 2 nd leaf was most remarkable and next the others were in order of 1 st leaf, 3 rd leaf and prophyll. Furthermore the degree of yellow leaves was in order of September, Apriland May-sowing.

Table 5 Sowing time and degree of yellow appearance

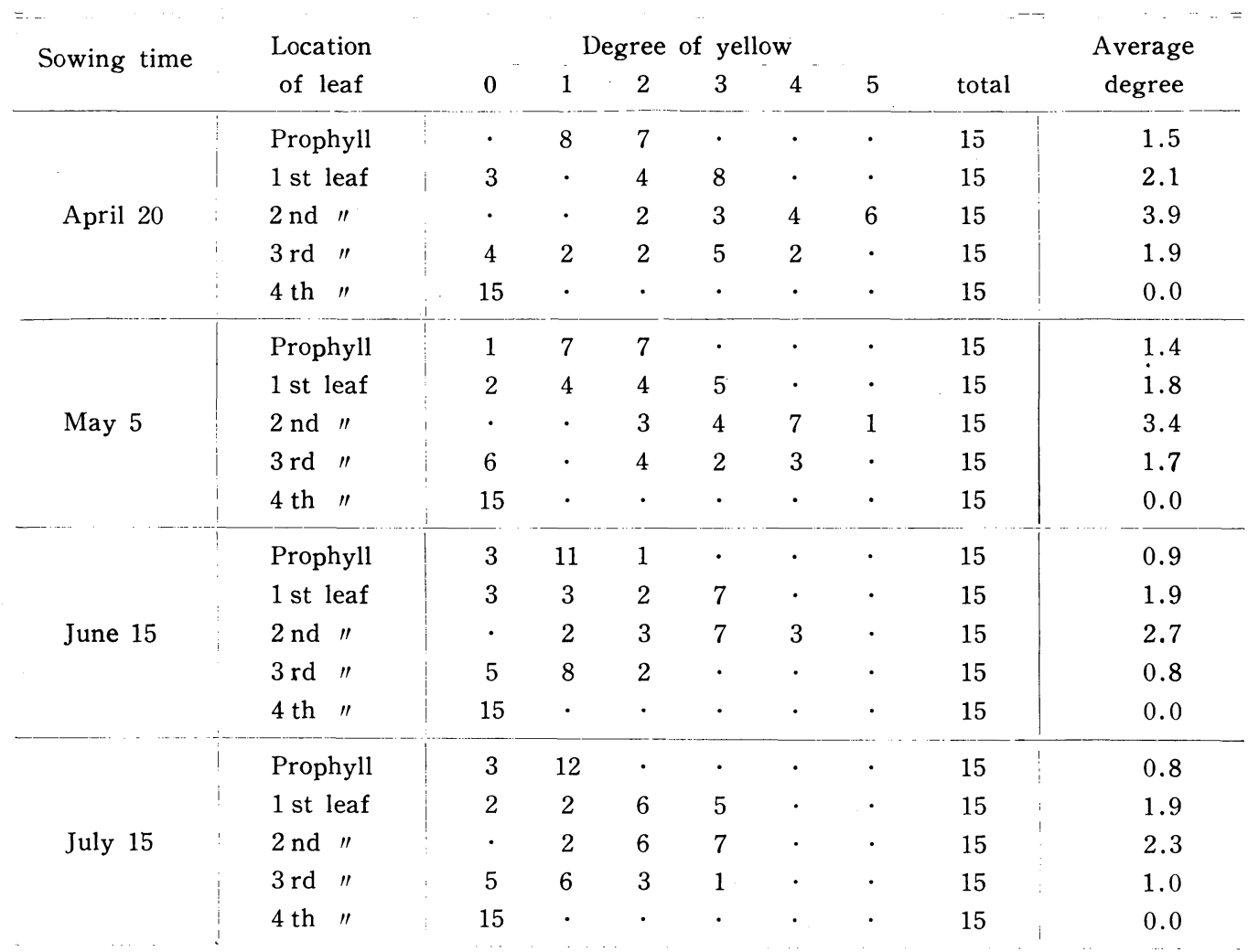




\begin{tabular}{|c|c|c|c|c|c|c|c|c|c|}
\hline \multirow{5}{*}{ August 15} & Prophyll & 4 & 11 & - & . & - & - & 15 & 0.7 \\
\hline & 1 st leaf & 3 & 4 & 3 & 5 & $\cdot$ & $\cdot$ & 15 & 1.7 \\
\hline & 2 nd $"$ & . & 1 & 5 & 8 & 1 & . & 15 & 2.6 \\
\hline & $3 \mathrm{rd} "$ & 5 & 8 & 2 & $\cdot$ & . & $\cdot$ & 15 & 0.8 \\
\hline & 4 th $"$ & 15 & $\cdot$ & . & $\cdot$ & . & $\cdot$ & 15 & 0.0 \\
\hline \multirow{5}{*}{$\begin{array}{c}\text { September } \\
20\end{array}$} & Prophyll & . & 7 & 8 & . & . & . & 15 & 1.5 \\
\hline & 1 st leaf & 3 & $\cdot$ & 4 & 8 & - & $\cdot$ & 15 & 2.1 \\
\hline & 2 nd $"$ & $\cdot$ & $\cdot$ & $\cdot$ & $\cdot$ & 2 & 13 & 15 & 4.9 \\
\hline & $3 \mathrm{rd} "$ & . & 4 & 6 & 5 & · & $\cdot$ & 15 & 2.1 \\
\hline & 4 th $"$ & 15 & $\cdot$ & . & · & - & $\cdot$ & 15 & 0.0 \\
\hline
\end{tabular}

\section{Summary and conclusion}

As described above, the behaviour of the new yellow character is summarized as follows. First (1) the optimum temperature for the growth of rice or the formation of chlorophyll brings usual green leaves, but somewhat low or high temperature for those inhibits their development and results in yellow leaf as the intermediate step. The degree of yellow appearance is most clear around $15^{\circ} \mathrm{C}$. And (2) it seems to have a relation to the condition of activity of germination or growth because the influence of temperature is not effective in soon after wetting or in a low temperature near $5^{\circ} \mathrm{C}$. Moreover (3) the character of these yellow leaves occurs usually until the 3 rd leaf at the seedling stage, and especially it is most pronounced at the 2 nd leaf.

\section{Literature cited}

Katayama, Y. and Shida, S. 1954. Further investigations on the inheritance of a variegated strain in rice. Jap. Jour. Breed. 3(No. 3, 4) :15-18.

Hara, S. 1944. Genetical studies on the chlorophyll characters in rice. I. Occurrence and inheritance of chlorina types. Jap. Jour. Genet. 20:15-19.

1946. Genetical studies on the chlorophyll characters in rice. II. Occurrence and in. heritance of xantha types. Jap. Jour. Genet. 21:1-9.

Morinaga, T. 1932. The chlorophyll deficiencies in rice. Bot. Mag., Tokyo 46:202-207. 